\title{
Extension of the right internal thoracic artery with the radial artery in extensive re-do coronary artery bypass grafting
}

\author{
Felix Fleissner*, Fabio lus, Axel Haverich and Issam Ismail
}

\begin{abstract}
Background: Patients with extensive coronary artery disease often require re-do coronary artery bypass grafting. However, autologous bypass material is sometimes sparse. Since long term patency of arterial graft material is superior to venous bypass grafting, we developed a technique to perform re-do total arterial coronary artery bypass grafting extending the right internal thoracic artery (RITA) with the radial artery (RA) in an end to end fashion to gain the needed length in patients with and without an open left thoracic artery (LITA).

Methods: We performed this approach in 27 consecutive patients (age: $67.93 \pm 7.51$ years). Data was analyzed retrospectively. 19 operations were first re-op, 6 were second re-op and two were third re-op procedures.

Results: Cardiopulmonary bypass time was 115.42 minutes ( \pm 31.92 minutes) with one OPCAB procedure, and clamp time was 55.09 minutes ( \pm 22.41 minutes) excluding 10 procedures performed on beating heart. Bypass grafting included the RCA, Cx and LAD. An average of 1.96 anastomoses were performed in each patient. Complication rate was low with one intra-operative apoplexy and one prolonged wound healing after harvest of the radial artery. One patient needed long term pulmonary assist. There was no intra-operative or early postoperative death.

Conclusion: The operational technique of elongation of the internal thoracic artery with the radial artery proved to be safe and feasible with acceptable operation times for a re-do procedure. We recommend this as an additional option to existing methods to perform a complete arterial revascularization mainly in patients with open left internal thoracic artery to LAD bypass.
\end{abstract}

\section{Background}

Coronary artery bypass grafting remains the gold standard for patients with multivessel disease and left main coronary artery disease [1]. The efficacy of coronary artery bypass grafting for patients with ischemic heart disease is dependent on the selected conduit. However, autologous bypass material is sparse, especially in re-do coronary artery bypass grafting cases. Meta-analyses suggest superiority of the radial artery over the saphenous vein concerning patency $[2,3]$. RA patency rates range from $83 \%$ to $93 \%$ at one to seven years after operation [4]. We therefore developed a technique to perform re-do total arterial coronary artery bypass grafting

\footnotetext{
* Correspondence: fleissner.felix@mh-hannover.de

Division of Cardiac, Thoracic, Transplantation and Vascular Surgery, Hannover
} Medical School, Hannover, Germany

(c) 2013 Fleissner et al.; licensee BioMed Central Ltd. This is an Open Access article distributed under the terms of the Creative Commons Attribution License (http://creativecommons.org/licenses/by/2.0), which permits unrestricted use, distribution, and reproduction in any medium, provided the original work is properly cited. extending the right internal thoracic artery (RITA) with $\mathrm{RA}$ in an end to end fashion to gain the needed length.

\section{Methods \\ Patients}

27 patients ( 25 male, 2 female, mean age 67.93 years) operated between 2005 and 2011 were enrolled in this observational study. All of them had received an extension of the right mammalian artery using the radial artery in our clinic. All of them were re-do cases (19 operations were first re-op, 6 were second re-op and two were third re-op procedures). The logistic STS Score for mortality was 9.08 ( \pm 5.14 , range 3.39-24.7) (Table 1 ). Two patients received previous venous bypass grafts only. We chose this approach in only a minority of patients at the surgeon's preference. In total, we performed 6025 CABG cases during this time period with approximately 5 percent cardiac 
Table 1 Patient's characteristics

\begin{tabular}{lcc}
\hline Variable & & \\
\hline Total patients $\mathrm{n}(100 \%)$ & 24 & $(100)$ \\
\hline Age yrs (SD) & 67.93 & $(7.51)$ \\
\hline Sex male $\mathrm{n}(\%)$ & 22 & $(81.48)$ \\
\hline BMI (SD) & 27.21 & $(3.46)$ \\
\hline LV function \% (SD) & 50.27 & $(12.9)$ \\
\hline Previous PTCA n (\%) & 9 & $(33.33)$ \\
\hline Previous Ml $\mathrm{n}(\%)$ & 9 & $(33.33)$ \\
\hline Previous CABG n (\%) & 24 & $(100)$ \\
\hline First re-op $\mathrm{n}(\%)$ & 19 & $(70.37)$ \\
\hline Second re-op $\mathrm{n}(\%)$ & 6 & $(22)$ \\
\hline Third/more than third re-op n (\%) & 2 & $(7.41)$ \\
\hline Elective $\mathrm{n}(\%)$ & 26 & $(96.30)$ \\
\hline Emergency $\mathrm{n}(\%)$ & 1 & $(3.70)$ \\
\hline STS Score SD & 9.08 & $(5.14)$ \\
\hline
\end{tabular}

re-do cases. In the other cases, we used either venous bypass grafts and or, if feasible, LITA or RITA grafts.

\section{Surgical technique}

All patients underwent ultrasound evaluation and a modified Allen test prior to operation of the RA. RA was harvested in a routine fashion using a no-touch technique in combination with low energy cautery. Anti-spasm prophylaxis consisted of $1 \mathrm{mg} / \mathrm{ml}$ papaverine applied topically. The surgical approach was a median sternotomy using a oscillating saw as standardized for re-do cases in our clinic, except for one patient who received a limited clamp shell approach. The RITA was prepared, left in situ and extended using the radial artery in an end to end fashion with a 7/0 suture (see Figure 1). We tried to perform the anasotmosis within the pericardium for further protection. Special care was undertaken to stay clear of the sternum for easier future access (5). The length of the extended RITA was sufficient to reach all three major vessels, and to perform up to three sequential bypasses if necessary. We generally used cardiopulmonary bypass except for one patient who was operated on during fibrillating heart. The aorta was clamped in 16 of the 27 patients. Two patients received a concomitant aortic valve replacement, both due to an aortic stenosis.

\section{Follow up}

End point was the occurrence of major cardiac event, defined as follows: 1) cardiogenic death; 2) myocardial infarction reported by patient or hospital admission for myocardial infarction reported by cardiologist; and 3) the need for revascularization (repeat operation or angioplasty reported by patient or cardiologist through follow up period.

\section{Statistical analysis}

Continuous data are expressed by mean $+-\mathrm{SD}$. Categorical numbers are summarized by reporting the percentages. Cumulated survival was estimated using the Kaplan and Meier method. Statistical analysis was

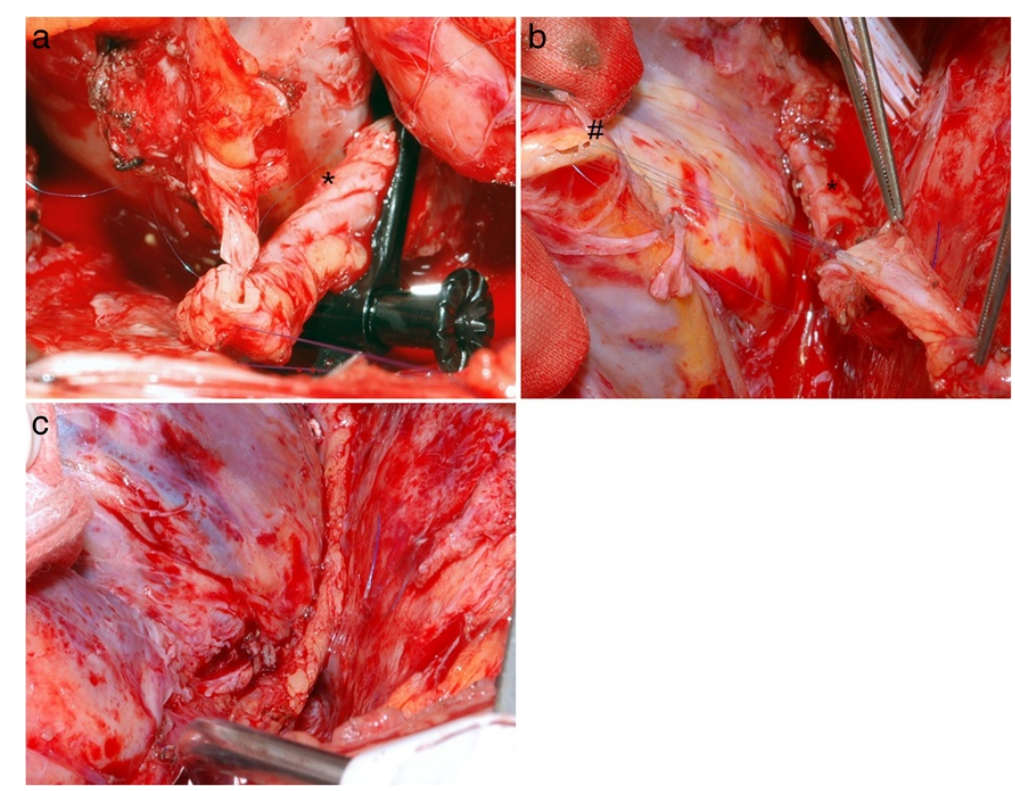

Figure 1 In-situ view of the extended RITA-RA bypass graft. a, $\left(^{*}\right)$ Right thoracic artery anastomosis (RITA) to (+) radial artery (RA) end to end anastomosis. b, extended (*) RITA-RA to (\#) RIVP anastomosis. c, The RITA-RA graft in situ. Of note the RITA-RA anastomosis is placed intrapericardial for better protection. 
performed using SPSS 20 package (SPSS Inc, Chicago, Il, USA).

\section{Ethics}

This retrospective study was approved by the Ethics Committee of Hanover Medical School and all patients gave their consent.

\section{Results}

Total operation time was 275.25 minutes ( \pm 59.62 minutes), cardiopulmonary bypass time was 115.42 minutes $( \pm 31.92$ minutes $)$ with one OPCAB procedure, and clamp time was 55.09 minutes $( \pm 22.41$ minutes), respectively. One patient received an IABP pre-operative and one patient postoperative. 9 procedures were performed on beating heart and one as an OPCAB procedure. An average of 1.96 anastomoses were performed in each patient (see Table 2). A detailed list of the performed anastomoses is found in Table 3. We were able to gain sufficient length with the extended RITA to perform up to four sequential bypasses to branches of the right coronary artery, the circumflex artery and the LAD, respectively. There were no intra-or early postoperative deaths. In average, the patients remained on the ICU for 3.14 days ( \pm 5.9 days), and left the primary hospital after an average of 9.4 days $( \pm 4.4$ days). One patient suffered from an intra-operative stroke. One patient displayed ST-elevations the first postoperative day. Emergent heart catheterization showed only a minor stenosis of the RITA-RA anastomosis and no denovo stenoses of the native coronaries (Figure 2). Postoperative course was uneventful, except for occurrence of atrial fibrillation in two patients and prolonged ventilation in one patient. One patient had a donor site infection which was treated by intravenous antibiotics. No patient developed ischemic forearm, hand or finger complications.

Follow up was complete. Median follow up was 41 months (ranging from 12 to 85 months). There was no death during follow up. Only 2 patients had a coronary angiogram during follow up due to angina or nonST elevation myocardial infarction. In both patients, the extended RITA graft was patent, however in one case

Table 2 Operational details and early postoperative complications

\begin{tabular}{lcc}
\hline Operational details & & \\
\hline Numbers of anastomosed vessels $\mathrm{n}(\mathrm{SD})$ & 1.93 & $(0.71)$ \\
\hline Opcab procedures $\mathrm{n}(\%)$ & 1 & $(3.7)$ \\
\hline Beating heart $\mathrm{n}(\%)$ & 9 & $(33.33)$ \\
\hline Cardiopulmonary bypass min (SD) & 115.42 & $(31.92)$ \\
\hline Clamp time min (SD) & 55.09 & $(22.41)$ \\
\hline complications & & \\
\hline Stroke $\mathrm{n}(\%)$ & 1 & $(3.7)$ \\
\hline Radial artery harvest site infection $\mathrm{n}(\%)$ & 1 & $(3.7)$ \\
\hline
\end{tabular}

Table 3 Overview of the performed bypass grafts in all patients

\begin{tabular}{lll}
\hline Performed bypass grafts & $\mathbf{n}$ & Numbers of anastomoses \\
\hline RITA-Rad-LAD & 4 & 1 \\
\hline RITA-Rad-PLA & 1 & 1 \\
\hline RITA-Rad-RIVP & 2 & 1 \\
\hline RITA-Rad-RCA & 1 & 1 \\
\hline RITA-Rad-RIVP-PLA & 9 & 2 \\
\hline RITA-Rad-PLA-RCA & 3 & 2 \\
\hline RITA-Rad- RIVP-LAD & 2 & 2 \\
\hline RITA-Rad-RIVP-RIM & 1 & 2 \\
\hline RITA-Rad-PLA-PLA-RIVP & 2 & 2 \\
\hline RIMA-Rad-RIVP-PLA1-LAD & 1 & 3 \\
\hline RITA-Rad-RCA-PLA-RIM & 1 & 3 \\
\hline
\end{tabular}

with a minor stenosis. There was a significant reduction in reported Angina. Pre-operative, 44.4\% $(n=12)$ of all patients reported angina class CCS $1-2$, and $44.4 \%$ ( $\mathrm{n}=$ 12) of patients were CCS class 3-4 (3 were unknown). Postoperative, only $7.4 \%(n=2)$ of patients were classified as CCS $3-4$ and $77.8 \%(n=21)$ were classified CCS 1-2 (4 patients were unable to classify their status of angina). The two patients remained in angina class II-IV despite an extensive antianginal medication. However, due to non cardiac related severe illnesses, no further intervention was undertaken in these patients.

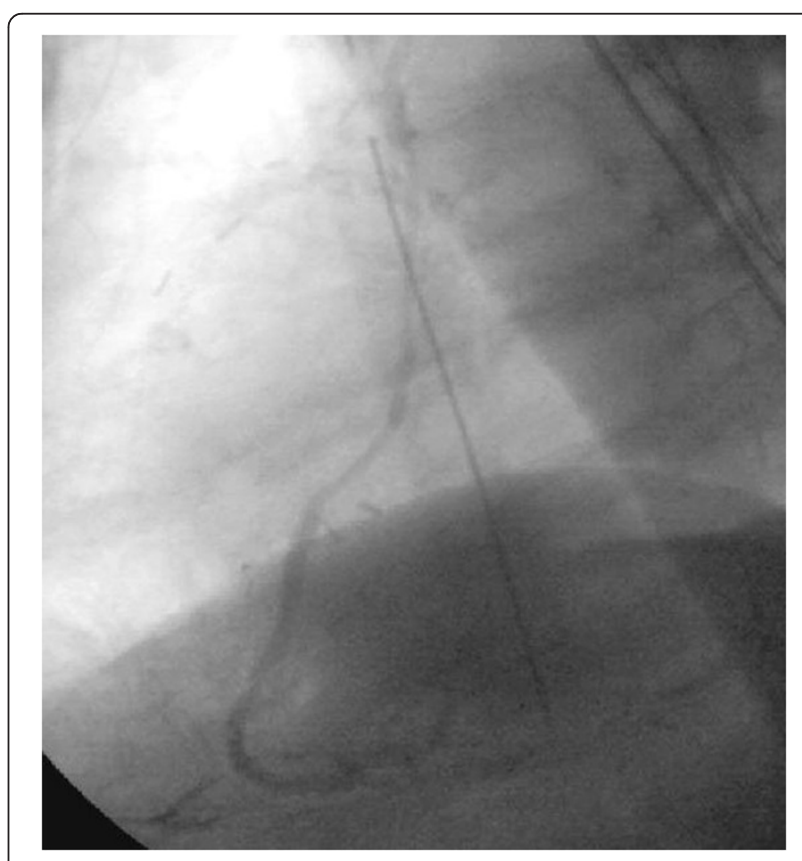

Figure 2 Postoperative coronary angiogram of the RIMA-RadRIVP-PLA2 bypass graft performed in patient number 17 . 


\section{Discussion}

By our case series we could show that extending the RITA using the radial artery is sufficient in length to revascularise all three major vessel areas. Early to midterm follow up revealed a low rate of necessary coronary angiograms and PTCAs due to angina and no death during follow up. Angina pectoris was significantly reduced in our patients. There was no intra-operative and no follow up mortality, even though the average STS score was high. Our mortality rate of $0 \%$ and complication rates are lower then those reported in the literature for re-do CABG operations [4], however this case series only includes a very limited number of carefully selected patients. In older series the observed mortality has been reported to be much higher ranging from 6.9 to $9.2 \%[5,6]$.

Limitations to our study are the retrospective approach and lack of a post-operative angiogram or computed angiography in all patients. However, there is so far no routine post- CABG angiogram established at our centre. Concerns about long term patency of the rather long bypass grafts have to be addressed in the future. Avoiding the use of vein grafts improves long term durability and limits donor site complications [7]. And, for especially the third-re-do cases autologous vein graft material can be simply inexistent. Redo cardiac surgery using the radial artery is well established with good results [8]. However, usually the RA is anastomosed to the proximal aorta showing acceptable results with a low mortality and postoperative complications, including a very low rate of spasm of the RA [8]. We do believe that using the extension of the radial artery avoids the proximal aortic anastomosis, which especially in re-do cases and calcified aortas can be a problem [9]. An interesting technique by Pehkonen et al. already introduced the anastomosis of the RA to the unharvested RITA [10]. However, the gained length of the RA alone anastomosed to the unharvested RITA is not sufficient to revascularize distal coronaries. Also, collateral flow through the RITA remains a problem. A possible weak point of this composite and sequential graft is that flow is dependent on a sequential in situ RITA graft. However, due to the expected longer patency over venous graft and our experience of a low complication rate early and midterm postoperative, we believe that this concept is safe and feasible for selected patients.

The length of the RITA-RA graft is also usually long enough to avoid crossing the midline beneath the sternum to avoid damage during a possible re-re-do operation.

\section{Conclusion}

In conclusion, we present a case series of re-do CABG patients with open LIMA-LAD bypass with excellent results using an extension of the RITA with the RA.

Abbreviations

(CABG): Coronary artery bypass grafting; (RA): Radial artery; (RITA): Right

internal thoracic artery; (LITA): Left thoracic artery.

\section{Competing interests}

The authors declare that they have no competing interests.

\section{Authors' contributions}

FF and II designed the study, performed the statistical analysis and wrote the manuscript, $\mathrm{AH}$ and $\mathrm{Fl}$ revised the manuscript and gave valuable contributions to the study. All authors read and approved the final manuscript.

\section{Acknowledgement}

Note: This Data was presented at the 2013 Annual Meeting of the German Society of Thoracic and Cardiovascular Surgery (DGTHG).

Received: 6 April 2013 Accepted: 1 July 2013

Published: 12 July 2013

\section{References}

1. Serruys PW, Morice MC, Kappetein AP, Colombo A, Holmes DR, Mack MJ, Ståhle E, Feldman TE, van den Brand M, Bass EJ, Van Dyck N, Leadley K, Dawkins KD, Mohr FW: Percutaneous coronary intervention versus coronary-artery bypass grafting for severe coronary artery disease. N Engl J Med 2009, 360(10):961-72.

2. Cao C, Manganas C, Horton M, Bannon P, Munkholm-Larsen S, Ang SC, Yan TD: Angiographic outcomes of radial artery versus saphenous vein in coronary artery bypass graft surgery: A meta-analysis of randomized controlled trials. J Thorac Cardiovasc Surg 2012, 4. in press.

3. Schwann TA, Engoren M, Bonnell M, Clancy C, Habib RH: Comparison of late coronary artery bypass graft survival effects of radial artery versus saphenous vein grafting in male and female patients. Ann Thorac Surg 2012, 94(5):1485-91.

4. Cale AR, Guvendik L, Griffin S, Cowen ME, Ngaage DL: Cale The impact of symptom severity on cardiac reoperative risk: early referral and reoperation is warranted. Eur J Cardiothorac Surg 2007, 32:623-628.

5. Salomon NW, Page US, Bigelow JC, Krause AH, Okies JE: M.T. Metzdorff Reoperative coronary surgery. Comparative analysis of 6591 patients undergoing primary bypass and 508 patients undergoing reoperative coronary artery bypass. J Thorac Cardiovasc Surg 1990, 100:250-259.

6. Velebit V, Simonet F, Mosimann E, Maurice J, Christenson JT, Schmuziger M: Velebit Reoperative myocardial revascularization: an analysis of 458 reoperations and 2645 single operations. Cardiovasc Surg 1994, 2:623-629.

7. Tranbaugh RF, Dimitrova KR, Friedmann P, Geller CM, Harris LJ, Stelzer P, Cohen BM, Ko W, DeCastro H, Lucido D, Hoffman DM: Coronary artery bypass grafting using the radial artery: clinical outcomes, patency, and need for reintervention. Circulation 2012, 126(11 Suppl 1):S170-5.

8. Tatoulis J, Buxton BF, Fuller JA: The radial artery in coronary re-operations. Eur J Cardiothorac Surg 2001, 19(3):266-72.

9. Zhang R, Zardo P, Haverich A, Ismail I: Elongation of right internal thoracic artery with radial artery for redo total arterial revascularization in patients with open left internal thoracic artery to left anterial descending artery graft. Eur J Cardiothorac Surg 2009, 36(1):206-7.

10. Pehkonen E, Seppänen S, Niemelä K, Majahalme S: Radial artery graft inflow from the undetached, unharvested RIMA: a method to avoid proximal anastomosis to the aorta in CABG surgery. Eur J Cardiothorac Surg 2000, 18(6):717-9.

\section{doi:10.1186/1749-8090-8-173}

Cite this article as: Fleissner et al:: Extension of the right internal thoracic artery with the radial artery in extensive re-do coronary artery bypass grafting. Journal of Cardiothoracic Surgery 2013 8:173. 